\title{
KEANEKARAGAMAN JENIS SEMUT (formicidae) DI KAWASAN HUTAN GUNUNG SELINDUNG DESA TWI MENTIBAR KECAMATAN SELAKAU KABUPATEN SAMBAS
}

\author{
(The Species Diversity Of Ant (Foermicidae) In Forest Area Of Gunung Selindung Twi \\ Mentibar Village Selakau Sub District Sambas Regency)
}

\author{
Rizal, Slamet Rifanjani, Siti Masitoh Kartikawati \\ Fakultas Kehutanan Universitas Tanjungpura Jl. Daya Nasional, Pontianak 78124 \\ Email: rizalpcpahutan@gmail.com
}

\begin{abstract}
Ants is a one of the biotic components in the forests of Kalimantan, this animal has a number of diverse species. This study aims to record and analyze the diversity of ant species in the area of Gunung Selindung of Twi Mentibar Village in Selakau Sub-District of Sambas Regency. The research method was purposive sampling where the placement of traps was done intentionally according to the presence of ants in three forest cover areas that is in open, medium and closed fores areas, divided into two area namely terestrial strata and arboreal. The results showed that there where nine species of ants (Formicidae) found in the Mount Selindung Forest area, namely black field ants (Formica sp), rang-rang (Oecophyllasp) pudak ant (Tapinoma melanocep), the black garden ant (Lasius niger), black ant (Dolichoderus teracicus), yellow crazy ant (Anoplolepis gracilipes), jumping ant (Harpagenethas Saltator), honey ant (Myrmecocystus sp), and sembadak ant (Odontomachus sp). The diversity index of the terestrial $\left(H^{\prime}\right)$, of three types of forest cover areas, namely closed areas $\left(H^{\prime}=0.63\right)$, moderate $\left(H^{\prime}=0.76\right)$, and open area strata $\left(H^{\prime}=0.73\right)$, all still showes the value of low species diversity; the species diversity index int the arboreal $\left(H^{\prime}\right)$, of the three types of forest cover areas namely closed area $\left(H^{\prime}\right)$, moderate $(H=0.61)$, and open area $\left(H^{\prime}=0.55\right)$ all still showes the value of low species diversity.
\end{abstract}

keyword: Ants, protected fores, , species diversity, Twi Mentibar Village

\section{PENDAHULUAN}

Semut termasuk ordo Hymenoptera dan famili formicidae, merupakan satwa yang mudah dikenali walaupun terdapat serangga lain yang sangat menyerupai semut. Koloni semut terbagi menjadi tiga kasta yaitu ratu, jantan, dan pekerja. Ratu lebih besar dari kasta lainya biasanya bersayap, walaupun sayap-sayap dilepaskan setelah proses perkawinan (Elzinga, 1987).

Semut merupakan kelompok hewan terestrial paling dominan di daerah tropik, memiliki peran penting dalam ekosistem sebagai predator, scavenger, herbivor, detritivor, dan granivor, serta memiliki peranan unik dalam interaksinya dengan tumbuhan atau serangga lain. Sejak kemunculannya, semut telah berkembang menjadi makhluk yang paling dominan di ekosistem teresterial. Dari 750.000 jenis serangga di dunia, 9.500 atau $1,27 \%$ di antaranya adalah semut (Holldobler dan Wilson, 1990).

Ekosistem merupakan suatu sistem yang terdiri dari makhluk hidup dan lingkungannya, terjadi interaksi antara keduanya untuk mempertahankan 
kehidupan. Hutan sebagai salah satu bentuk ekosistem memiliki karakteristik habitat yang berbeda untuk jenis tertentu. Deforestasi atau perubahan fungsi dari hutan menjadi non-hutan juga berperan dalam perubahan ekosistem dan jenis di dalamnya.

Serangga sebagai salah satu fauna yang ada, merupakan aspek yang menarik untuk dikaji lebih lanjut. Serangga adalah organisme yang banyak ditemukan dan beragam jenisnya di dunia dan masih belum banyak dari keberagamannya yang terdeskripsikan secara jelas. Masih sangat sedikit pemanfaatan jenis serangga yang potensial untuk dijadikan sebagai indikator biologi untuk penilaian terhadap perubahan ekosistem (Jurzenski dkk, 2012).

Keberadaan semut di permukaan tanah (terestrial) dan di atas pohon (arboreal) cukup beragam karena kedua daerah ini memiliki ketersedian pasokan makanan yang cukup beragam juga. Kawasan Gunung Selindung adalah kawasan yang ditetapkan sebagai Hutan lindung, kawasan ini mulai mengalami reforestasi dari lahan yang awal mulanya terbuka sampai mempunyai berbagai kondisi tutupan tajuk. Kawasan ini memiliki keanekaragaman hayati yang tinggi baik flora maupun fauna termasuk semut. Penelitian ini bertujuan untuk mendata keanekaragaman jenis semut di kawasan Gunung Selindung Desa Twi Mentibar Kecamatan Selakau Kabupaten Sambas.

\section{METODOLOGI PENELITIAN}

Penelitian dilaksanakan di kawasan Gunung Selindung Desa Twi Mentibar
Kecamatan Selakau Kabupaten Sambas, selama 2 bulan yaitu bulan Maret sampai April 2018 dilanjutkan identifikasi jenis semut dan analisis data. Jalur pengamatan ditetapkan berdasarkan terestrial dan arboreal kondisi tutupan lahan yaitu areal terbuka, sedang dan tertutup. Peletakan jebakan dilakukan dengan sengaja (purposive sampling) dengan memperhatikan tipe hutan dan keberadaan sarang semut.

Penempatan jebakan di setiap jalur dan tipe jebakan, yaitu:

1. Bagian terestrial mengunakan jebakan jatuh berumpan (Pitfall Traps)

2. Bagian arboreal menggunakan perangkap kertas berperekat (Fly Sheet) dengan ukuran $10 \times 10 \mathrm{~cm}$ dengan ketinggian sekitar 6 meter.

Setiap tipe hutan dilakukan tiga pemasangan perangkap dengan tiga ulangan yaitu pukul 07.00-17.00, pukul 17.00-07.00 dan pukul 07.00-17.00 di hari berikutnya.

Analisis data diukur meliputi Indeks Keanekaragaman Jenis (H') Shannon Wiener Index (Odum, E. P. 1996), dengan kriteria sebagai berikut : suatu komunitas yang memiliki nilai $\mathrm{H}^{\prime}<1$ maka dikatakan komunitas tersebut rendah jika nilai $\mathrm{H}^{\prime}$ antara 1-3 dikatakan komunitas tersebut sedang, sedangkan jika nilai $\mathrm{H}^{\prime}>3$ maka dikatakan nilai tersebut sangat stabil atau tinggi.

Indeks Kemerataan Jenis (e) (Odum 1993) yaitu dengan kriteria komunitas lingkungan berdasarkan indeks kemerataan: $\mathrm{E}<0,50$ komunitas tertekan $0,5<\mathrm{E}<0,75$ komunitas labil $0,75<\mathrm{E}<$ 1 komunitas stabil. Indeks Kekayaan Jenis 
(DMg) nilai kekayaan jenis digunakan untuk mengetahui keanekaragaman jenis berdasarkan jumlah jenis pada suatu ekosistem. Indeks yang digunakan adalah Indeks kekayaan jenis Margalef dengan kriteria.

$\mathrm{DMg}<2,5 \quad=\quad$ menunjukan tingkat kekayaan yang rendah

2,5 $>\mathrm{DMg}>4=$ menunjukan tingkat kekayaan jenis yang sedang

$\mathrm{DMg}>4 \quad=\quad$ menunjukan tingkat kekayaan yang tinggi

\section{HASIL DAN PEMBAHASAN}

Jenis semut yang ditemukan

Hasil penelitian ditemukan 9 jenis semut (formicidae) dengan perbandingan di kawasan terestrial delapan jenis semut dan pada arboreal sebanyak enam jenis semut (tabel 1). Jumlah total individu sebanyak 874 individu yang terdiri dari 572 individu ditemukan pada teristerial dan 302 individu pada strata tengah pohon.

Jenis dan jumlah semut yang di temukan pada dua lokasi penelitian

Tabel 1. Jenis dan Jumlah semut yang ditemukan pada dua lokasi penelitian (Types and number of ants found in two research sites)

\begin{tabular}{llcc}
\hline No & Jenis Semut & Terestrial & Arboreal \\
\hline 1 & semut sembadak (Odontomachus $s p$ ) & $\mathrm{V}$ & - \\
2 & semut hitam lapangan (Formica $\mathrm{sp}$ ) & $\mathrm{V}$ & $\mathrm{V}$ \\
3 & semut pudak (Tapinoma melanocep) & $\mathrm{V}$ & - \\
4 & semut kebun hitam (Lasius niger) & $\mathrm{V}$ & $\mathrm{V}$ \\
5 & semut hitam (Dolichoderus teracicus) & $\mathrm{V}$ & $\mathrm{V}$ \\
6 & semut gila kuning (Anoplolepis gracilipes) & $\mathrm{V}$ & $\mathrm{V}$ \\
7 & semut pelompat (Harpagenethas saltator) & $\mathrm{V}$ & $\mathrm{V}$ \\
8 & semut madu (Myrmecocystus $\mathrm{sp}$ ) & $\mathrm{V}$ & - \\
9 & Semut rang-rang (Oecophylla sp) & - & $\mathrm{V}$ \\
\hline & Jumlah & 8 & 6 \\
\hline
\end{tabular}

Semut rang-rang (Oecophylla sp) hanya ditemukan pada arboreal serta 3 jenis semut hanya ditemukan pada terestrial yaitu semut sembadak (Odontomachus sp), semut pudak (Tapinoma melanocep), semut madu (Myrmecocystus sp). Penelitian di kawasan hutan Gunung Selindung dilakukan pada 3 tipe habitat yaitu, areal terbuka, sedang dan areal tertutup. Jenis semut yang ditemukan pada ke 3 tipe habitat yaitu semut hitam lapangan (Formica sp) serta semut pudak (Tapinoma melanocep), sedangkan 1 jenis semut yang ditemukan pada areal tutupan sedang yaitu semut pelompat (Harpagenethas saltator) karena jenis semut ini memiliki pesebaran terbatas. 
Tabel 2. Jenis Semut Berdasarkan Habitat Teresterial (Types of Terrestrial Habitat Ants)

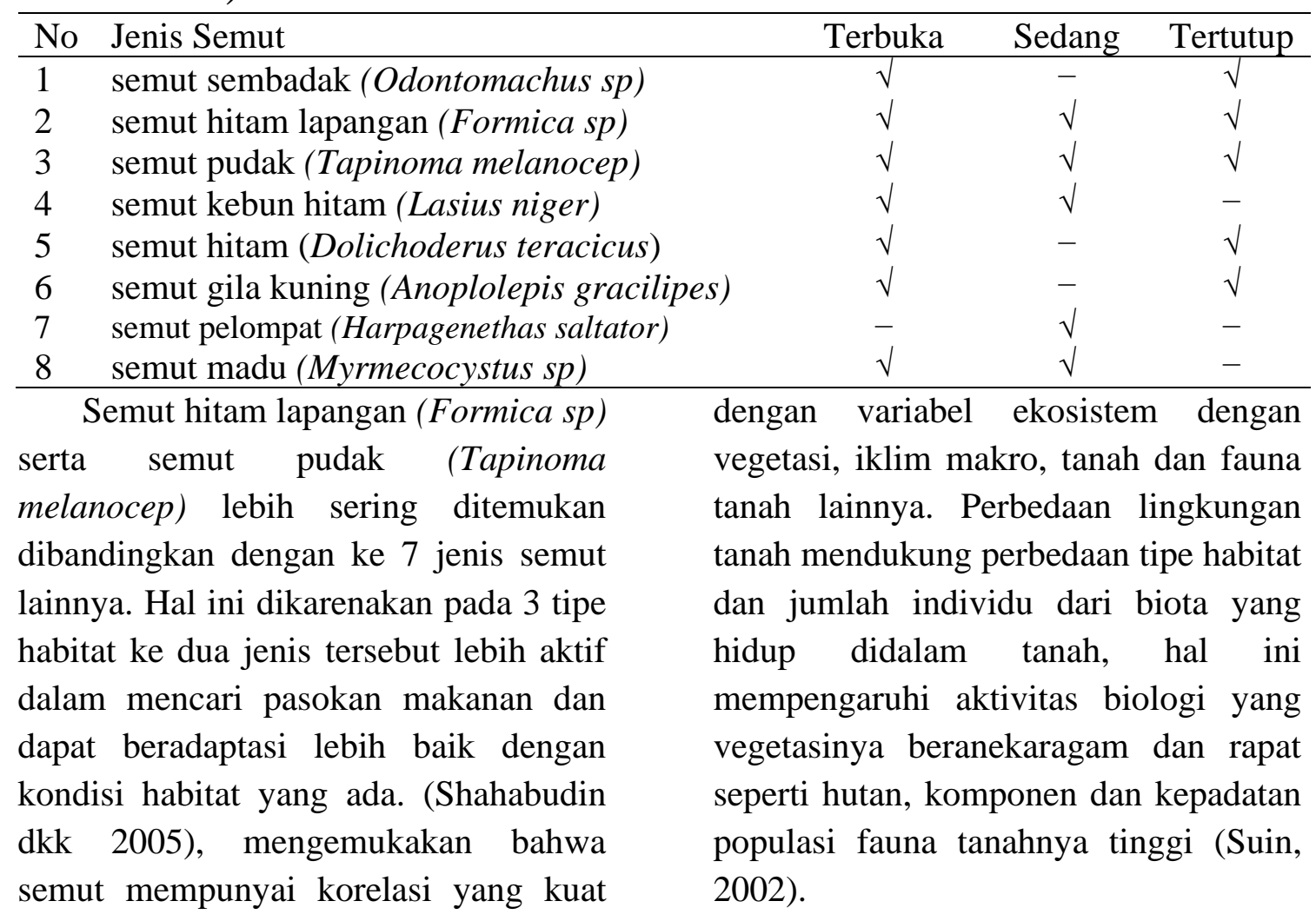

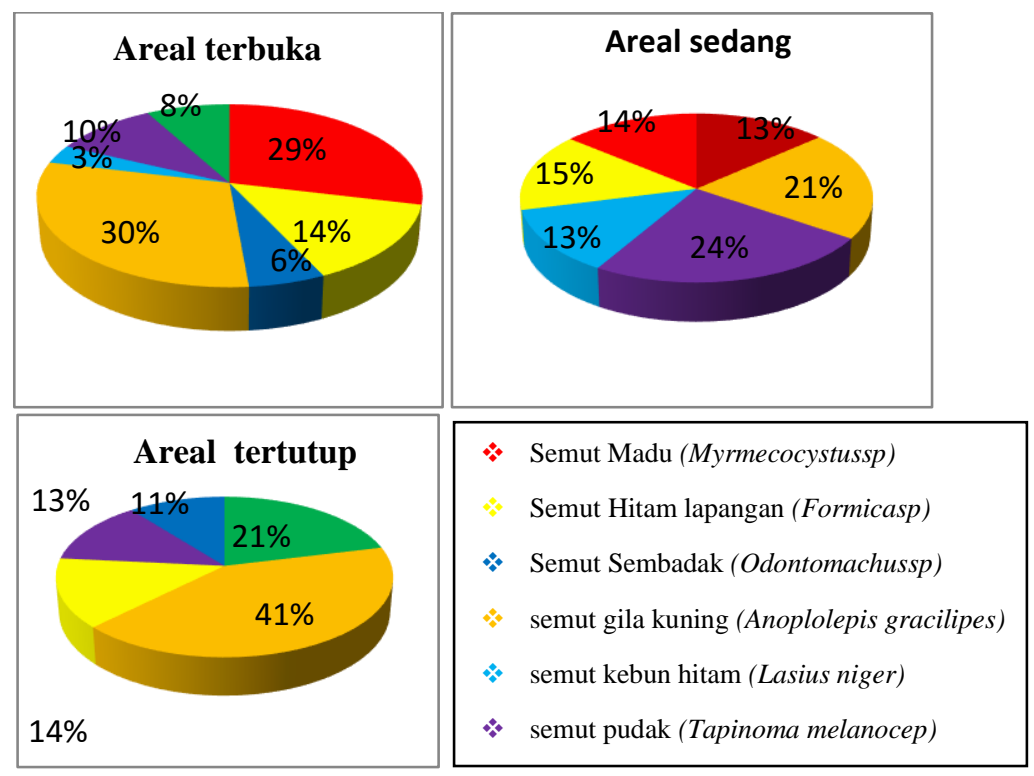

Gambar 1. Presentase perbandingan jenis semut terestrial pada tiga 3 lokasi tutupan kawasan hutan (Percentage comparison of terrestrial ant species in three 3 forest cover locations) 
Berdasarkan hasil penelitian jumlah total semut yang ditemukan di habitat terestrial sebanyak 572 individu dari ke 3 tipe tutupan hutan yang paling dominan ditemukan semut gila kuning (Anoplolepis gracilipes) pada areal tertutup (41\%) dan terbuka (30\%) sedangkan pada areal yang memiliki tutupan sedang ditemukan (24\%) semut pudak (Tapinoma melanocep) pada areal tertutup memiliki tutupan yang lebih tinggi sehingga lebih disukai oleh jenis semut dibandingkan pada areal terbuka dan areal sedang.

Perubahan habitat sangat mempengaruhi keberadaan semut. Respon semut yang sangat sensitif terhadap perubahan habitat menjadikan semut dapat digunakan sebagai bioindikator dari gangguan habitat, termasuk juga pengaruh aplikasi pestisida. Beberapa spesies semut mampu memanfaatkan terjadinya peningkatan suhu melalui peningkatan aktivitas dan jumlah koloni, yang menyebabkan perubahan struktur komunitas melalui mekanisme kompetisi. Keberadaan tempat bersarang yang sesuai juga mempengaruhi keberadaan semut (Agosti D, dkk 2000).

Indeks Keanekaragaman Jenis (H')

Indeks keanekaragaman jenis merupakan keanekaragaman jenis yang terdapat dalam suatu kawasan hutan. Semakin tinggi nilai $\left(H^{\prime}\right)$ maka tingkat keanekaragaman jenis semakin besar atau jenis-jenis yang dijumpai semakin banyak. Berdasarkan penelitian Indeks kekayaan jenis (DMg) merupakan jumlah dari total jenis dalam satu komunitas, tergantung dari ukuran jumlah individu dan waktu yang diperlukan untuk mengetahuinya. Kekayaan jenis dalam suatu nilai tunggal digambarkan dengan indeks diversitas. Indeks kemerataan jenis (e) adalah indeks yang digunakan untuk mengetahui pemerataan pembagian individu yang merata diantara jenis. Artinya semakin tinggi nilai kemerataan jenis maka penyebaran suatu jenis akan semakin merata dalam komunitas tersebut.

Tabel 3. Keanekaragaman jenis (H'), Kekayaan Jenis (DMg), dan Kemerataan Jenis (e) yang terdapat dipermukaan teristerial pada Kawasan Hutan Gunung Selindung Desa Twi Mentibar. (Species diversity index (H), species richness (DMg), and evenness type (e)which is on the terrestrial surface in the Gunung Selindung Village Forest area, Twi Mentibar)

\begin{tabular}{lccc}
\hline \multicolumn{1}{c}{ Tipe Habitat } & $\mathrm{H}^{\prime}$ & DMg & E \\
\hline Terbuka (A) & 0,73 & 43,75 & 0,52 \\
Sedang(B) & 0,76 & 31,94 & 0,50 \\
Tertutup (C) & 0,63 & 27,19 & 0,42 \\
\hline
\end{tabular}

Nilai keanekaragaman jenis semut ditiga lokasi tutupan hutan memiliki nilai dibawah $<1$ maka dikatakan jenis tersebut rendah. Semakin tinggi tingkat gangguan habitat, keanekaragaman maupun keberadaan spesies semut yang ditemukan cenderung semakin sedikit karena adanya ganguan seperti 
kebakaran hutan, perambahan hutan, dan aktifitas manusia.

Keberadaan semut yang terdapat pada kawasan hutan Gunung Selindung tergantung pada habitatnya, karena habitat masing-masing mempunyai ketersedian pasokan makanan dan energi yang cukup untuk jenis semut tersebut. Pada areal tertutup memiliki tutupan kanopi sebesar $70 \%$ dibandingkan dengan areal terbuka dan sedang, sehingga pada areal tertutup lebih disukai oleh banyak jenis semut sebab areal tertutup masih mempunyai kelembaban yang stabil sehingga dapat menciptakan iklim mikro bagi perkembangbiakan semut (Tabel 4) (Wibowo \& Wulandari 2014).

Tabel 4. Jenis Semut Pada Arboreal (Types of Ants on Arboreal)

\begin{tabular}{clccc}
\hline No & Jenis Semut & Terbuka & Sedang & Tertutup \\
\hline 1 & semut hitam lapangan (Formica sp) & $\sqrt{ }$ & $\sqrt{ }$ & $\sqrt{ }$ \\
2 & semut rang-rang (Oecophyllasp) & $\sqrt{ }$ & $\sqrt{ }$ & $\sqrt{ }$ \\
3 & semut kebun hitam (Lasius niger) & $\sqrt{ }$ & - & $\sqrt{ }$ \\
4 & semut hitam (Dolichoderus teracicus smith) & $\sqrt{ }$ & - & $\sqrt{ }$ \\
5 & semut gila kuning (Anoplolepis gracilipes) & - & - & $\sqrt{ }$ \\
6 & semut pelompat (Harpagenethas saltator) & - & $\sqrt{ }$ & - \\
\hline
\end{tabular}

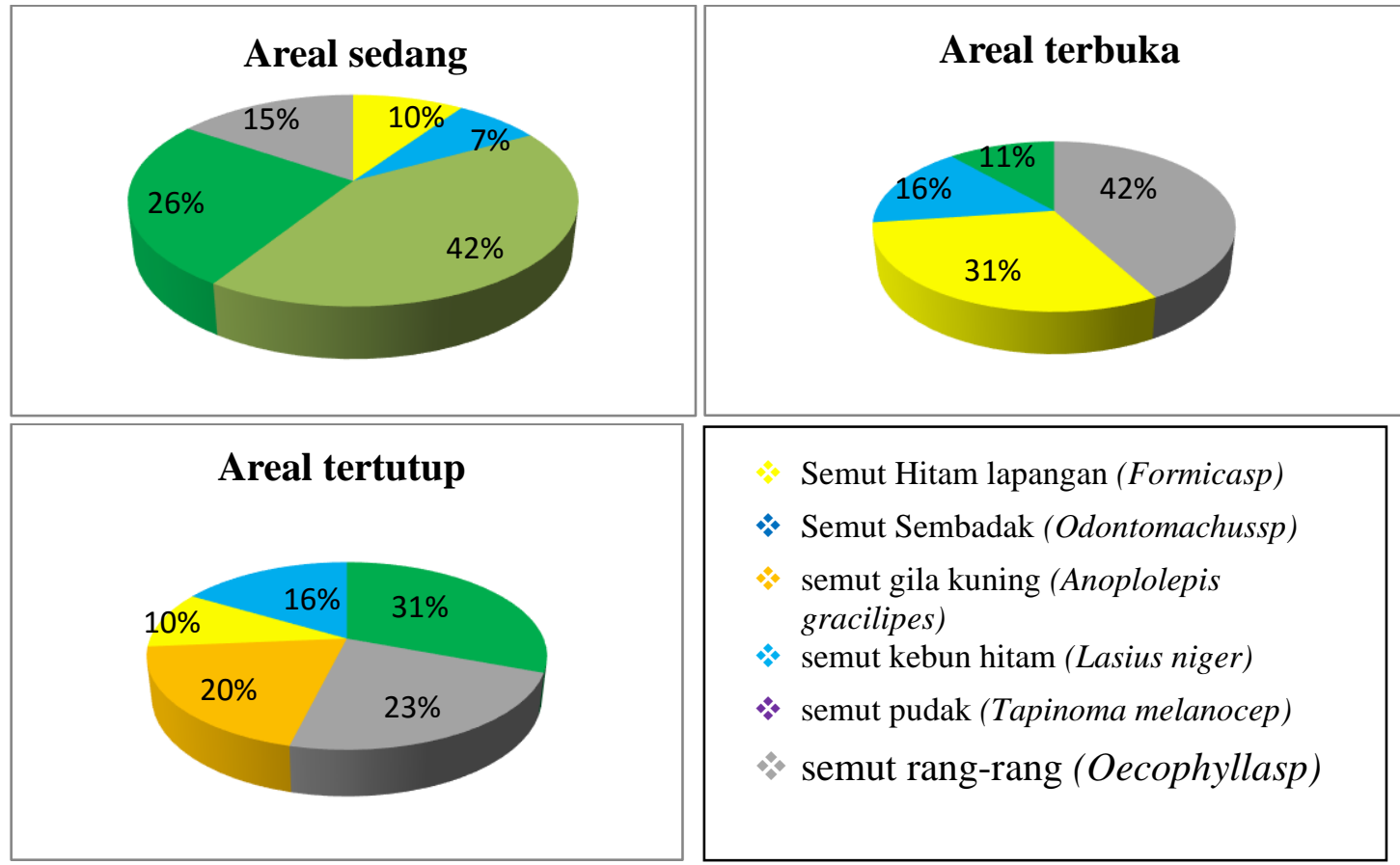

Gambar 2. Presentase perbandingan jenis semut arboreal pada tiga 3 lokasi tutupan kawasan hutan (Percentage comparison of arboreal ant species at three 3 forest area cover locations)

Pada strata arboreal yang ditemukan 108 individu, pada areal ditutupan sedang ditemukan jenis yang dominan sebanyak $42 \%$ yaitu jenis semut pelompat (Harpagenethes saltator), dan ditemukan jenis yang dominan sebanyak $42 \%$ jenis semut rang-rang (Oecophylla sp) pada diareal 
terbuka jenis semut yang dominan 23\% jenis semut rang-rang (Oecophylla $s p$ ). Gangguan yang dimaksud adalah gangguan dari aktifitas manusia. Pernyataan ini sesuai dengan (Chung dan Maryati 1996) yang menyatakan bahwa habitat yang terganggu karena kehadiran manusia akan memiliki diversitas semut yang lebih rendah jika dibandingkan dengan habitat yang tidak mengalami gangguan.

Tabel 5. Keanekaragaman jenis (H'), Kekayaan Jenis (DMg), dan Kemerataan Jenis yang terdapat pada arboreal di Kawasan Hutan Gunung Selindung Desa Twi Mentibar (Species diversity index $\left(H^{\prime}\right)$, species richness (DMg), and evenness of species found in arboreal in the Gunung Selindung Village Forest area, Twi Mentibar)

\begin{tabular}{lccc}
\hline \multicolumn{1}{c}{ Tipe Habitat } & H' & DMg & E \\
\hline terbuka (A) & 0,55 & 44,29 & 0,40 \\
sedang (B) & 0,61 & 48,69 & 0,50 \\
tertutup (C) & 0,67 & 49,23 & 0,54 \\
\hline
\end{tabular}

Indeks keanekaragaman jenis $\left(\mathrm{H}^{\prime}\right)$, dari tiga tipe habitat yaitu areal tertutup sedang dan areal terbuka seluruhnya berada pada nilai di bawah $<1$ artinya memiliki keanekaragaman hayati rendah. Kelimpahan jenis (e) pada areal tertutup sangat tinggi yaitu $(\mathrm{e}=0,54)$, serta areal sedang $(\mathrm{e}=0,50)$.

Mengemukakan (Agosti D, dkk 2000) keberadaan semut sangat terkait dengan kondisi habitat dan beberapa faktor pembatas utama yang mempengaruhi keberadaan semut yaitu suhu rendah, habitat yang tidak mendukung untuk pembuatan sarang, sumber makanan yang terbatas serta daerah jelajah yang kurang mendukung.

Kawasan Gunung Selindung mempunyai tingkat kerapatan tajuk yang beraneka ragam sehingga pada kawasan Gunung Selindung menunjukan bahwa semut hitam lapangan (Formica $s p$ ) dan semut rangrang (Oecophylla sp) lebih banyak ditemukan di 3 tipe habitat hal ini disebabkan oleh faktor iklim serta tingkat dari tutupan tegakan pohon yang yang terdapat pada kawasan Gunung Selindung masih rapat. Hal ini sesuai dengan hasil penelitian (Wibowo, Wulandari. 2014), yang menyebutkan bahwa habitat rendah.

\section{Kesimpulan}

Hasil penelitian menunjukan bahwa indeks keanekaragaman jenis yang terdapat pada tipe tutupan hutan baik terestrial maupun arboreal memiliki nilai <1 hal ini didukung dengan keanekaragaman jenis terestrial 0,76 dan pada arboreal ditemukan 0,67. Artinya hutan ini memiliki keanekaragaman jenis semut yang rendah.

\section{DAFTAR PUSTAKA}

Agosti D, Majer JD, Alonso LE, Schultz TR, 2000 editor. Ants: Standard Methods for Measuring and Monitoring Biodiversity. Volume 3. Amerika Serikat (US): Smithsonian Inst. hlm 25-34.

Chung dan Maryati. 1996. A comparative study of the ant 
fauna in primary and secondary forest in Sabah, Malaysia. Di dalam: Edward DS, Booth WE, Choy SC, editor. Tropical Rainforest Research-Current Issues. Dodrecht (NL): Kluwer Academic.

Elzinga, R. J. 1987. Fundamentals of Entomology. Third Edition, Prentice-Hall, Inc. Englewood Cliffs, New Jersey 07632. USA.

Holldobler, B. dan Wilson, I. 1990. The Ants. Cambridge Massachusetts: Harvard Univ Pr.feromon.

Jurzenski J, Albrecht M, Hoback WW. 2012. Distribution and diversity of ant genera from selected ecoregions across Nebraska. The Prairie Naturalist 44(1):17-29.

Odum, E. P. 1996. Dasar-dasar ekologi (T. Samingan, Terjemahan). Yogyakarta: Gadjah Mada University Press.

Odum EP. 1993. Dasar-dasar Ekologi. Edisi Ketiga. Universitas Gajah Mada.

Suin MN. 2002. Metode Ekologi. Universitas Andalas : Padang.

Shahabuddin Hidayat P. Noerdjito W A, \& Manuwoto S. 2005. Review: Penelitian Biodiversitas Serangga di Indonesia: Kumbang Tinja (Coleoptera: Scarabaeidae) dan Peran Ekosistemnya. Biodiversitas. 6 (2).ISSN: 1412033x.

Wibowo C \& Wulandari SD. 2014. Keanekaragaman insekta tanah pada berbagai tipe tegakan pohon di hutan pendidikan Gunung walat dan hubungannya dengan lingkungan. Jurnal Silvikultur Tropika 5 (1): 33-42. 